\title{
OUTCOMES AFTER PRIMARY SURGERY OF UTERINE SARCOMA: RETROSPECTIVE CASE SERIES STUDY.
}

Ana Vegas, Irene López, Nerea Montero, Carmen Martín, Francisco J. Pérez, Carlos Millán, Enrique Moratalla.

\section{Introduction}

University Hospital HM Montepríncipe. Madrid.

Uterine sarcomas are rare tumors, they constitute $8 \%$ of uterine tumors. There are different subtypes of uterine sarcomas based on the hystopathological exam: leiomyosarcoma, endometrial stromal sarcoma, undifferentiated uterine sarcoma and adenosarcoma. Natural history and response to the treatment is different depending on the tumor subtype. More evidence is needed to clarify and individualize the best treatment in each case.

\section{Objective}

We sought to determine the time to recurrence and survival after primary surgical treatment of uterine sarcomas in our hospital.

\section{Results}

8 patients

\section{Patients and methods}

- Retrospective, case series study.

- All patients diagnosed of uterine sarcoma with primary surgical treatment.

- October 2010 and January 2017.

- Main outcomes: Time to recurrence and survival.

\begin{tabular}{|c|c|c|c|c|c|}
\hline Type & Frequency & FIGO Stages & $\begin{array}{l}\text { Mean time to } \\
\text { recurrence }\end{array}$ & Overall survival & $\begin{array}{l}\text { Five year } \\
\text { survival rate }\end{array}$ \\
\hline \multirow{2}{*}{$\begin{array}{c}\text { Endometrial Stromal } \\
\text { sarcoma (ESS) }\end{array}$} & \multirow[t]{2}{*}{$50 \%(4)$} & $75 \% \mathrm{IB}$ & \multirow{5}{*}{21,4 months } & \multirow[t]{2}{*}{ - } & \multirow{2}{*}{$66,7 \%$} \\
\hline & & $25 \%$ IIIC & & & \\
\hline \multirow{2}{*}{$\begin{array}{l}\text { Leiomyosarcoma } \\
\text { (LMS) }\end{array}$} & \multirow[t]{2}{*}{$37 \%(3)$} & $33 \%$ IIIB & & \multirow{3}{*}{12,75 months } & \\
\hline & & $66 \% \%$ IV & & & \\
\hline $\begin{array}{l}\text { Undifferenciated } \\
\text { sarcoma (US) }\end{array}$ & $12,5 \%(1)$ & IV & & & \\
\hline
\end{tabular}

\section{Conclusion}

Being conscious of the limitations of our study, the small size and the heterogeneity of our series our findings suggests that uterine sarcoma is a devastating disease, with a poor prognosis and high local recurrence and metastatic rates. Nowadays treatment is based on radical surgery, chemotherapy and radiotherapy, however, further studies are needed to identify new therapies. 